ORIGINAL ARTICLE

\title{
Prevalence and Predictors of Dysmenorrhea, its Effects and Coping Mechanism among Adolescent
}

\author{
NADIA KHAN JAWAD ${ }^{1}$, ZULFIQAR ALI ${ }^{2}$, SHUMAILA KHAWAJA KHAIL ${ }^{3}$, AASIA FOZIA ${ }^{4}$, NADIA PERVAIZ ${ }^{5}$, FATIMA \\ REHMAN ${ }^{6}$ \\ ${ }^{1}$ Assistant Professor Obstetrics \& Gynecology, Jinnah International Hospital, Women Medical College, Abbottabad \\ ${ }^{2}$ Consultant Gynaecologist Obstetrics \& Gynecology, Mardan Women Hospital Sheikh Maltoon Town, Mardan \\ ${ }^{3}$ Specialist Registrar Obstetrics \& Gynaecology, Unit A Lady Reading Hospital, Peshawar \\ ${ }^{4}$ Senior Registrar Obstetrics \& Gynaecology, Jinnah International Hospital, Abbottabad \\ ${ }^{5}$ Senior Registrar Obstetrics \& Gynaecology, A ward Qazi Hussain Ahmed Medical Complex, Nowshera \\ ${ }^{6}$ Assistant Professor Obstetrics \& Gynaecology department, Mardan Medical Complex/ Bacha Khan Medical College, Mardan \\ Corresponding Author: Dr Shumaila Khawaja Khail, Email: dskhawaja@gmail.com, Cell: +923319201220
}

\begin{abstract}
Background and Aim: Dysmenorrhea is one of the most common gynecological disorders in the world. The current study aims to know the prevalence of dysmenorrhea and its management practices among adolescent girls. The study also aim to assess predictors of dysmenorrhea treatment options.

Materials and Methods: This institutional-based cross-sectional study was carried out at Obstetrics \& Gynaecology department of Mardan Women Hospital, Sheikh Maltoon Town Mardan and Jinnah International Hospital, Abbottabad from June 2020 to November 2020. Pretested self-administrated and a semi-structured questionnaire was used for data collection from volunteer adolescent girls to take part in this study. The outcome and exposure variables association was evaluated through a multi regression model and chi-square test. Dysmenorrhea risk was reported by taking the odds ratio at a confidence interval of $95 \%$. SPSS version 20 was used for data analysis and statistical significance was considered at $p<0.05$.

Results: Of the total 680 questionnaires, 601 (88.4\%) were completed. The response rate and dysmenorrhea prevalence were $88.4 \%$ and $53.3 \%$ respectively. The mean age of the adolescents was $16.3 \pm 1.92$. While mean age for Menarche was $12.41 \pm 1.62$. A significant difference $(t=5.78, p<0.001)$ between dysmenorrhea and nondysmenorrhea age girls was $(16.81 \pm 1.98)$ and $(12.56 \pm 1.65)$ respectively. The common symptom of waist pain among participants was $(345,57.4 \%)$. The prevalence of participants taking Over-the-counter (OTC) drugs for menstrual symptoms was $191(31.8 \%)$. Dysmenorrhea's severity and age were the two significant predictors for the prospect of taking a dysmenorrhea pharmacological agent.

Conclusion: Our study concluded that a higher prevalence of dysmenorrhea was observed among adolescents compared to Menarche which adversely affects the routine major activities. A significant association between selfreported dysmenorrhea and the abnormal menstrual cycle was found. Adolescents must be educated early on about the safety and efficacy of various dysmenorrhea management options.
\end{abstract}

Keywords: Dysmenorrhea, Adolescence, Menarche.

\section{INTRODUCTION}

Dysmenorrhea is referred to as cramps, severe, and recurrent pain during menstruation. Dysmenorrhea could be either with identifiable pelvic disorders or primary pathology without visible pelvic [1]. Menstrual cramps could because by various factors such as prostaglandins F2 $\alpha$ production, hyper prostaglandins uterine production further causing arterial vasoconstriction and myometrium hypercontractility [2]. Within the first two days of menses, prostaglandins higher prevalence was found in dysmenorrheal women compared to the nondysmenorrheal women. The severe pain uterine activities were more intense than intrauterine pressure and labor above thresholds tissue profusion [3]. Dysmenorrhea is the most frequently appeared in adolescence as a gynecological disorder. Dysmenorrhea prevalence in adolescence varies from $50 \%$ to $95 \%$ worldwide [4]. This might be caused by different definitions of dysmenorrhea, lack of severe pain measurement standard methods, and various studies carried out in different age groups [5]. A study conducted on university students found a higher prevalence of dysmenorrhea (93\%) among Egyptian women who had painful menstruation [6]. Other few studies followed the dysmenorrhea prevalence $89 \%, 72 \%[7,8]$.
Substantial losses in terms of finance extend beyond individual standards due to medical care, decreased productivity, medications cost, impaired routine activities. Out of dysmenorrhea affected women, about $20 \%$ of women faced difficulties in performing routine activities during their menstrual cycle [9]. In the USA, dysmenorrhea cause 140 million working hours losses due to the lower output of these women despite their desire to work during their cramps [10]. Besides, about US $\$ 4.2$ billion losses to Japan's economy due to dysmenorrhea [11]. Socioeconomic status and routine activities are often affected by dysmenorrhea along with hyperemesis gravidarum (HG) risk for the future. Another study reported five-time higher chances of $H G$ development in adolescence and middle age dysmenorrhea [12]. For severe dysmenorrhea, 10 fold increases in dysmenorrhea were reported. This could be due to the assumption that nausea and vomiting caused by prostaglandins and cytokines in hyperemesis patients are related to nausea and vomiting caused by severe dysmenorrhea. Thus, early diagnosis and treatment of severe nausea and vomiting in patients with a history of severe dysmenorrhea contribute to a reduction in $\mathrm{HG}$ morbidity [13]. Despite the dysmenorrhea common occurrence and substantial effects 
on routine activities, many women fail to seek medical treatment and reporting pain, hence, it is undertreated and undiagnosed disease [14]. Menstrual cramps screening should be done in adolescent girls due to only a few women (14.2\%) seeks medical care [15]. A very few studies have been carried out on predictors and prevalence of dysmenorrhea in developing nations such as Pakistan. Hence, an attempt has been made to determine the prevalence, predictors, effects, and coping mechanism of dysmenorrhea among adolescent girls.

\section{MATERIALS AND METHODS}

This institutional-based cross-sectional study was carried out at Obstetrics \& Gynaecology department of Mardan Women Hospital, Sheikh Maltoon Town Mardan and Jinnah International Hospital, Abbottabad from June 2020 to November 2020. Pretested self-administrated and a semistructured questionnaire was used for data collection from volunteer adolescent girls to take part in this study. The outcome and exposure variables association was evaluated through a multi regression model and chi-square test. Dysmenorrhea risk was reported by taking the odds ratio at a confidence interval of $95 \%$. Statistical software was used for sample size calculation with the following assumptions confidence level 95\%, power statistics $80 \%$, significance level $5 \%$, absolute precision $5 \%$, and proportion $67 \%$ and $10 \%$ non-response rate. The final sample size was 680 . The age range of the participants was between 12 years and 19 years. Unmarried girls were selected with purposive sampling technique who had not given birth, but experienced menstrual cycles. The participants with an uncompleted questionnaire and do not know answers were excluded from this study. The data collection procedure included open and closed-end questions, menstrual characteristics, its effects, and coping mechanism. Questions completeness and clarity were assessed in the pretested questionnaire.

The exposure variables were divided into three main parts. Age, education levels, and participants' menstrual characteristics were included in the first part. Chronicle age was $12-15$ years or $16-19$ years, menarche age was $(<13$, and 13-16) and menstrual cycles (regular or irregular), flow nature (heavy, moderate and light), cycle length $(<21$ days or > 21 days), dysmenorrhea family history and menstruation days $(<3$ or $>3)$. Secondly, quality of life affected by menstrual the pain of the participants include menstrual pain duration $(>3$ or $<3$ ), the intensity of the pain (severe, moderate, mild), unnecessary irritations $(y / n)$, and physical activities restrictions. The coping mechanism was the third part which includes self-medication (yes/no), home remedies (relaxation, hot application, and herbs), ignored menstrual pain, and menstrual pain lessening through physical exercises. SPSS version 20 was used for data analysis. A Chi-square test was performed to compare the outcome and exposure variables. The associations among various factors such as Menarche age, educational level, staying place, chronicle age, flow nature and history of menstruation, dysmenorrhea family history, and menstruation duration were estimated with a multiple regression model. For all the analysis, 95\% confidence interval and $p<0.05$ was considered statistically significant.

\section{RESULTS}

Of the total 680 questionnaires, 601 (88.4\%) were completed. The response rate and dysmenorrhea prevalence were $88.4 \%$ and $53.3 \%(95 \% \mathrm{Cl}, 64.0-71.0)$ respectively. The mean age of the adolescents was $16.3 \pm$ 1.92. While mean age for Menarche was $12.41 \pm 1.62$. A significant difference $(t=5.78, \quad p<0.001)$ between dysmenorrhea and non-dysmenorrhea age girls was (16.81 $\pm 1.98)$ and (12.56 \pm 1.65$)$ respectively. The common symptom of waist pain among participants was (345, $57.4 \%$ ). The prevalence of participants taking Over-thecounter (OTC) drugs for menstrual symptoms was 191 (31.8\%). Dysmenorrhea's severity and age were the two significant predictors for the prospect of taking a dysmenorrhea pharmacological agent. Most of the participants with dysmenorrhea 420 (70\%) were of age range between 16 years and 19 years. About 445 (74\%) of the participants and respondents were living with their parents and found statistically significant $(p<0.03)$. Additionally, the first menstruation experience between adolescents was of age 13 years to 15 years with dysmenorrhea prevalence $360 \quad(60 \%)$. But found statistically insignificant $(p>0.02)$. However, the proportion of irregular menstruation in dysmenorrhea was 174 (29\%) and was found significant $(p<0.02)$. Yet, associations among menstrual cycle length ( $p>0.015)$, menstruation duration $(p>0.10)$, menstrual flow $(p<0.47)$, and family history $(p>0.57)$ as shown in Table-2 and Figure-3 were found insignificant. Table-1 demonstrate the adolescence and menarche age distribution among study population. Dysmenorrhea affects adolescents is summarized in Table 3. The history of menstruation pain intensity was reported in 217 adolescent girls. Among which severe, moderate, and mild pain was found in 86,76 , and 55 respectively. It was found statistically significant $(p<0.03)$. The majority of respondents $(63.6 \%)$ had pain last for more than three days but was found insignificant. The physical activities affected by menstrual pain $(23 \%)$ were found significant $(p<0.03)$. Figure-1 and 2 illustrate the prevalence of dysmenorrhea (present or absent) in adolescence and menarche girls respectively.

Table-1. Menarche and adolescence girls age distribution

\begin{tabular}{|l|l|l|l|} 
Age (years) & \multicolumn{1}{|c|}{ Yes n (\%) } & \multicolumn{1}{l|}{ No $\mathbf{n}(\%)$} & \multicolumn{1}{c|}{ Total n (\%) } \\
\hline Adolescence age & & & \\
\hline $12-15$ & $134(74)$ & $47(26)$ & $181(30.1)$ \\
\hline $16-19$ & $322(76.7)$ & $98(23.3)$ & $420(69.9)$ \\
\hline Total & $456(75.9)$ & $145(24.1)$ & $601(100)$ \\
\hline Menarche Age & & & \\
\hline$<12$ & $22(29.1)$ & $54(71.9)$ & $76(12.7)$ \\
\hline $13-15$ & $214(59.5)$ & $146(40.5)$ & $360(59.9)$ \\
\hline$>15$ & $113(68.5)$ & $52(31.5)$ & $165(27.4)$ \\
\hline Total & $349(58.1)$ & $252(41.9)$ & $601(100)$ \\
\hline
\end{tabular}

The participants and respondents were asked about their dysmenorrhea experience and the coping mechanism they adopted for dysmenorrhea. Menstrual pain was ignored by $57 \%$ as a high proportion. However, most of them took action with self-medication (35\%), hot applications (12\%), physical exercise (15\%), herbs $(7 \%)$, and relaxation (24\%). Additionally, about $20 \%$ consulted 
the physician. But all these had insignificance associations with dysmenorrhea as demonstrated in Table 3.

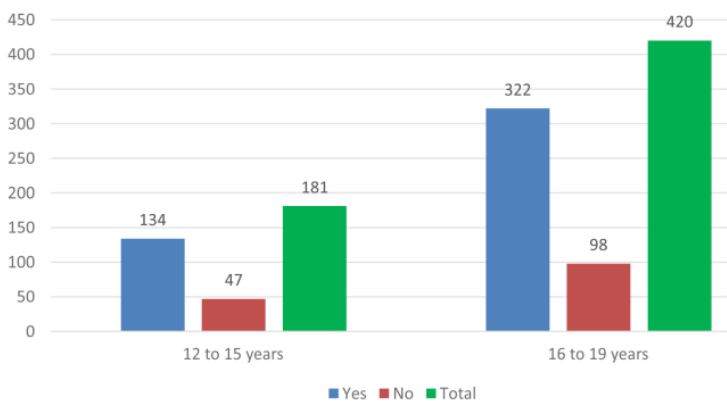

Figure-1. Prevalence of dysmenorrhea $(y / n)$ in adolescence girls

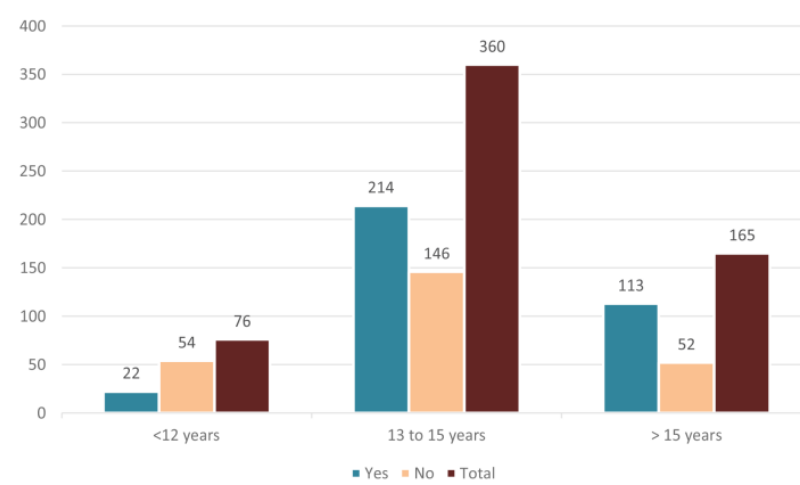

Figure-2 Prevalence of dysmenorrhea $(y / n)$ in Menarche girls

Table-2 Univariate analysis of dysmenorrhea experiences among the participants

\begin{tabular}{|l|l|l|}
\hline Variables & $\begin{array}{l}\text { Frequency } \\
\text { (n) }\end{array}$ & $\begin{array}{l}\text { Percentage } \\
(\%)\end{array}$ \\
\hline Waist pain & 345 & 57.4 \\
\hline Prevalence of OTC taking & 191 & 31.8 \\
\hline Living with their parents & 445 & 74 \\
\hline First menstruation experience & 360 & 60 \\
\hline Irregular menstruation & 174 & 29 \\
\hline Menstrual Duration $>3$ & 413 & 68.7 \\
\hline Cycle length>21 & 389 & 64.7 \\
\hline Family history & 190 & 31.6 \\
\hline
\end{tabular}

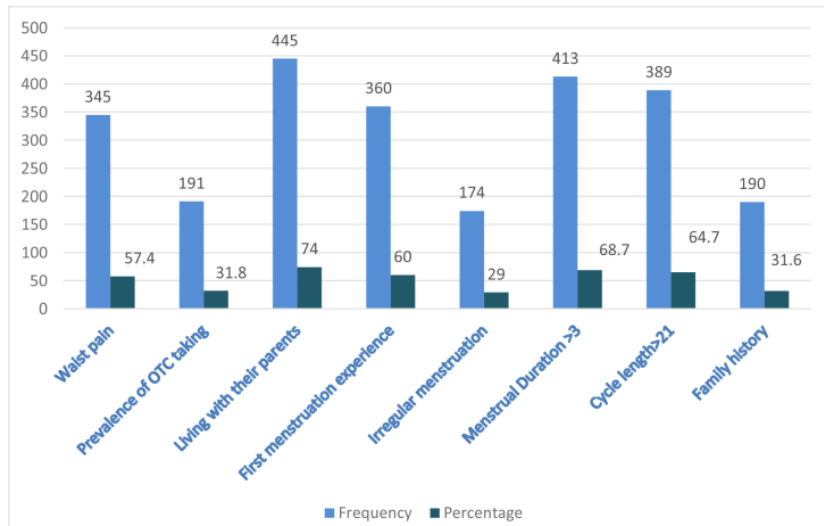

Figure 3. Prevalence of dysmenorrhea experiences among the participants
Table 3. Prevalence of adopted strategy and coping mechanism by study population

\begin{tabular}{|l|l|l|l|l|}
\hline Parameters & Dysmenorrhea & & Total & p-value \\
\hline Yes (\%) & No (\%) & & $>0.87$ \\
\hline Pain Ignored & & & & $>0.1$ \\
\hline Yes & $274(80.1)$ & $68(19.9)$ & 342 & \\
\hline No & $178(68.7)$ & $81(31.3)$ & 259 & \\
\hline Self-Medications & & & & $>0.42$ \\
\hline No & $160(76.2)$ & $50(23.8)$ & 210 & \\
\hline Physical Exercise & $109(27.8)$ & $284(72.2)$ & 391 & \\
\hline Yes & $24(26.7)$ & $66(73.3)$ & 90 & $>0.18$ \\
\hline No & $318(61.2)$ & $193(37.8)$ & 511 & \\
\hline Relaxations & & & & $>0.19$ \\
\hline Rest & $69(47.9)$ & $75(52.1)$ & 144 & \\
\hline None & $131(28.7)$ & $326(71.3)$ & 457 & \\
\hline Herbs & $37(88.1)$ & $5(11.9)$ & 42 & \\
\hline Hot Applications & $61(84.7)$ & $11(15.3)$ & 72 & \\
\hline Physician Consulted & & & & \\
\hline Yes & $113(94.2)$ & $7(5.8)$ & 120 & \\
\hline No & $371(77.13)$ & $10(22.97)$ & 481 & \\
\hline & & & & \\
\hline
\end{tabular}

\section{DISCUSSION}

The dysmenorrhea prevalence established in our study was $53.3 \%(95 \% \mathrm{Cl}, 64.0-71.0)$. Comparing to the other studies, a higher prevalence of dysmenorrhea was reported (83.5\%) [16] and 74.3\% [17]. Another study found $41 \%$ prevalence which was lower than our findings [18].Individual pain perceptions and dysmenorrhea definition might be the reasons for prevalence differences. Another study reported a $33.7 \%$ prevalence of dysmenorrhea in adolescent girls [19]. Irregular menstrual cycle history was compared to adolescent, dysmenorrhea self-reported, and participants who did not live with parents. After potential confounder adjustment, irregular menstrual cycle history observed with dysmenorrhea self-reported and odds association. Previous studies suggested an association between dysmenorrhea and menstrual irregularities. Another study found associations among various factors such as stress, the irregular cycle of menstruation, age, cigarettes, dysmenorrhea, and smoking habits [20, 21]. Similarly, in dysmenorrhea irregular menstrual cycle was found $29 \%$ in adolescent girls. Another study findings matched our results with irregular menstrual prevalence ranges from 10 to $37 \%$ in menstruating women [22]. Dysmenorrhea and irregular menstruation could be caused by insignificance association. The two main responsible factors are prostaglandins production by endometrium with dysmenorrhea, in turn, increased pain and uterine contraction during menstrual flow. Ischemic pain and uterine contraction caused by vasoconstriction cloud be increased by vasopressin [23].

Previously conducted studies found a significant association between dysmenorrhea experience and physical activities [24]. Their results matched our findings of physical restriction in $23 \%$ of adolescents during their menstruation. Another study found $24 \%$ prevalence of physical activities restriction [25]. A higher prevalence of respondents experienced menarche between dysmenorrheal patients of age 13 years and 15years. The previous study reported like our study that dysmenorrhea mostly occurred in early menarche [26]. However, menarche and dysmenorrhea experience had no significant association. About 18.8\% (113) respondents had dysmenorrhea with menarche age $>15$ years in our study. While other studies found increasing prime dysmenorrhea and early menarche [27]. Therefore, menstruation physical 
activities and menarche psychological impacts should be addressed in reproductive health educations.

Furthermore, about $57 \%$ of adolescent girls ignored the menstrual pain including both (presence and absence) of dysmenorrhea. However, a number of coping mechanisms and adopted strategies such as selfmedication (35\%), hot applications (12\%), physical exercise (15\%), herbs $(7 \%)$, and relaxation $(24 \%)$. Additionally, about $20 \%$ consulted the physician. But all these had insignificance associations with dysmenorrhea. These findings of our study matched another study's results which shows the significance of our study [28-30]. Finally, another study conducted on early treatment of dysmenorrhea includes but no limitation to use heating pad [31] which matched our study findings (12\%). About $7 \%$ used herbs to relieve menstrual pain. Another study reported one-third population of female's utilized nonpharmacological relief methods for pain [32].

\section{CONCLUSION}

Our study concluded that a higher prevalence of dysmenorrhea was observed among adolescents compared to Menarche which adversely affects the routine major activities. A significant association between selfreported dysmenorrhea and the abnormal menstrual cycle was found. Adolescents must be educated early on about the safety and efficacy of various dysmenorrhea management options.

\section{REFERENCES}

1. E. J. R. Bunga, E. Lukas, J. L. Tumedia, and S. M. T. Chalid, "The Effect of Pyridoxine on Prostaglandin Plasma Level in Patients with Primary Dysmenorrhea," Indones. J. Obstet. Gynecol., vol. 6, no. 4, pp. 239-242, 2018.

2. H. Fitriani and Achmad, "The Effect of Hypnotherapy on Primary Dismenore in Adolescents," JMCRH, vol. 1, no. 2, pp. 285-291, 2018.

3. K. A. J. Widyanata, P. I. Daryaswanti, and I. G. Y. Putra, "Physical Activity and Meditation to Reduce Primary Dysmenorrhea in Adolescent," in \&th International Nursing Conference (INC 2017), 2017, vol. 3, no. Inc, pp. 18-20.

4. U. O. Abaraogu, C. S. Tabansi-ochiogu, and E. S. Igwe, "Effectiveness of exercise therapy on pain and quality of life of patients with primary dysmenorrhea : a systematic review with meta-analysis Egzersiz tedavisinin primer dismenoreli hastaların ağrı ve yaşam kalitesi üzerine etkinliği :," Turk J Phys Rehab, vol. 62, no. 4, pp. 346-354, 2016.

5. The American College of Obstetricians and Gynecologists, "Dysmenorrhea: painful periods," Frequently asked questions, 2015. [Online]. Available: https://www.acog.org//media/ForPatients/faq046.pdf?dmc=1\&ts=20190917T08385 36272 . [Accessed: 17-Sep-2019].

6. K. Acheampong et al., "Prevalence and Predictors of Dysmenorrhea, Its Effect, and Coping Mechanisms among Adolescents in Shai Osudoku District , Ghana," Hindawi Obstet. Gynecol. Internatiional, vol. 2019, 2019.

7. K. A. Calis, "Dysmenorrhea," Medscape, 2018. [Online]. Available: https://emedicine.medscape.com/article/253812overview\#a6. [Accessed: 18-Sep-2019].

8. Ji-Ah Song, M. Lee, E. Min, M.-E. Kim, G. Fike, and M.-H. Hur, "Effects of aromatherapy on dysmenorrhea: A systematic review and meta-analysis," Int. J. Nurs. Stud., vol. 84, pp. 1-11, 2018.

9. E. P. K. Ameade, A. Amalba, and B. S. Mohammed, "Prevalence of dysmenorrhea among University students in
Northern Ghana ; its impact and management strategies," BMC Womens. Health, vol. 18, no. 39, pp. 1-9, 2018

10. Chen CX, Shieh C, Draucker CB, Carpenter JS. Reasons women do not seek health care for dysmenorrhea. J Clin Nurs 2018;27 (1-2):e301-8.

11. Ameade EPK, Mohammed BS. Menstrual pain assessment: Comparing verbal rating scale (VRS) with numerical rating scales (NRS) as pain measurement tools. Int $\mathrm{J}$ Women's Health Wellness 2016;2(1):17. 3

12. Bourdel N, Alves J, Pickering G, Ramilo I, Roman H, Canis M. Systematic review of endometriosis pain assessment: How to choose a scale? Hum Reprod Update 2015;21(1):136-52.

13. Kapadi R, Elander J. Pain coping, pain acceptance and analgesic use as predictors of health-related quality of life among women with primary dysmenorrhea. Eur J Obstet Gynecol Reprod Biol 2020;246(1):40-4.

14. Lazaridou A, Kim J, Cahalan CM, Loggia ML, et al. Effects of cognitive-behavioral therapy (CBT) on brain connectivity supporting catastrophizing in fibromyalgia. Clin J Pain 2017;33 (3):215-21.

15. Lazaridou A, Franceschelli O, Protsenko K, Napadow V, Edwards R. (318) The association between mindfulness, catastrophizing and pain interference among patients with fibromyalgia: The moderating role of mindfulness. J Pain 2017;18 (4):S54-5.

16. Armour M, Parry K, Al-Dabbas MA, et al. Self-care strategies and sources of knowledge on menstruation in 12,526 young women with dysmenorrhea: A systematic review and metaanalysis. PLoS One 2019;14(7):e0220103.

17. Bush D, Brick E, East MC, Johnson N. Endometriosis education in schools: A New Zealand model examining the impact of an education program in schools on early recognition of symptoms suggesting endometriosis. Aust N Z J Obstet Gynaecol 2017;57 (4):452-7.

18. Wong CL, Ip WY, Choi KC, Lam LW. Examining self-care behaviors and their associated factors among adolescent girls with dysmenorrhea: An application of Orem's self-care deficit nursing theory. J Nurs Scholarsh 2015;47(3):219-27.

19. Fahs B, Perianes MB. Transnational engagement: Designing an ideal menstrual health $(\mathrm{MH})$ curriculum-stories from the field. In: The Palgrave Handbook of Critical Menstruation Studies, London, UK: Palgrave Macmillan 2020:449-65.

20. Hanel PH, Vione KC. Do student samples provide an accurate estimate of the general public? PLoS One 2016;11 (12):e0168354. 55. Attarchi M, Darkhi H, Kashanian M, et al. Characteristics of menstrual cycle in shift workers. Global J Health Sci 2013;5 (3):163-72.

21. A. Qurota and Mukhoirotin, "Spiritual relaxation to reduce dysmenorrhea: a quasy experimental," medisains, J. Ilm. ilmu-ilmu Kesehat., vol. 17, no. 3, pp. 57-61, 2019.

22. N. Habiibi, M. S. L. Huang, W. Y. Gan, R. Zulida, and S. M. Safavi, "Prevalence of Primary Dysmenorrhea and Factors Associated with Its Intensity Among Undergraduate Students : A Cross-Sectional Study," pain Manag. Nurs., vol. 16, no. 6, pp. 855-861, 2015.

23. E. Sinaga et al., Manajemen Kesehatan Menstruasi. Jakarta: Universitas Nasional, IWWASH, Global One, 2017. 14. J. Jo and S. H. Lee, "Heat therapy for primary dysmenorrhea: A systematic review and meta-analysis of its effects on pain relief and quality of life," Sci. Rep., vol. 8, no. October, pp. 18, 2018.

24. B. Berger, A. Boning, H. Martin, A. Fazeli, D. D. Martin, and J. Vagedes, "Personal perception and body awareness of dysmenorrhea and the effects of rhythmical massage therapy and heart rate variability biofeedback-A qualitative study in the context of a randomized controlled trail," Complement. Ther. Med., vol. 45, pp. 280-288, 2019.

25. Scollo, S., La Camera, G., Neri, S., Grasso, C., Cubisino, R., Bonsignore, C., La Rosa, V., Astuto, M.Acquired 
angioedema of the glottis, larynx and neck in a patient affected by SLE: Case report(2018) European Journal of Molecular and Clinical Medicine, 5, pp. 16-19. DOI: 10.5334/ejmcm.247

26. R. P. Smith, The Clinical Classification and Causes of Dysmenorrhea. Springer International Publishing, 2018. 18. V. De Sanctis et al., "Primary Dysmenorrhea in Adolescents : Prevalence , Impact and Recent Knowledge," Pediatr. Endocrinol. Rev., vol. 13, no. 2, pp. 465-473, 2015.

27. M. Akbarzadeh, N. Tayebi, and M. Abootalebi, "The Relationship between Age at Menarche and Primary Dysmenorrhea in Female Students of Shiraz Schools," Shiraz E-Medical J., vol. 18, no. 9, 2017.

28. A. Cetin, "Evaluation of Biological and Sociodemographic Factors Affecting Dysmenorrhea," cureus, vol. 12, no. 5, pp. $1-8,2020$.
29. M. Al-Jefout et al., "Dysmenorrhea: Prevalence and Impact on Quality of Life among Young Adult Jordanian Females," J. Pediatr. Adolesc. Gynecol., vol. 28, no. 3, pp. 173-185, 2015.

30. S. Lghoul, M. Loukid, and M. K. Hilali, "Saudi Journal of Biological Sciences Prevalence and predictors of dysmenorrhea among a population of adolescent' $\mathrm{s}$ schoolgirls ( Morocco )," Saudi J. Biol. Sci., vol. 27, no. 7, pp. 1737-1742, 2020.

31. A. Pejc 'ic' and S. Jankovic', "Risk factors for dysmenorrhea among young adult female university students," Ann Ist Super Sanità, vol. 52, no. 1, pp. 98-103, 2016.

32. Armour M, Parry K, Manohar N, et al. The prevalence and academic impact of dysmenorrhea in 21,573 young women: a systematic review and meta- analysis. J Womens Health 2019;28:1161-71. 